\title{
ИЗУЧЕНИЕ СТРУКТУРНО-ДИНАМИЧЕСКИХ ИЗМЕНЕНИЙ ОСНОВНЫХ ФОНДОВ В РОССИИ
}

\author{
(c) 2019 Кравченко Антон Валерьевич \\ соискатель кафедры экономической теории \\ Самарский государственный экономический университет, Россия, Самара \\ E-mail: iwtvtgb@gmail.com
}

Поступательное развитие экономики должно опираться на материально-техническую базу и инфраструктурные элементы, таким образом, изучение состояния основных фондов и их воздействия на основные макроэкономические показатели является актуальной задачей решаемой экономической наукой. Целью проведенного исследования является изучение количественных изменений происходящих в структуре основных фондов на протяжении 1990-2018 гг. Для решения поставленной задачи были использованы общенаучные и экономико-статистические методы. В качестве основных результатов можно назвать: установлено снижение доли основных фондов в структуре национального богатства России, что связано с ростом нематериальных активов в связи с цифровизацией экономики; несмотря на рост среднегодовой стоимости основных фондов в абсолютном выражении, в относительном исчислении имеет место замедление процесса наращивания активов; на протяжении 1990-2018 гг. наибольшая доля основных средств сосредоточена в промышленности, но значительно увеличился удельный вес транспорта и связи, что связано с переходом к цифровой экономике; коэффициент обновления выше коэффициента выбытия, что указывает на наращивание активов. Полученные результаты могут быть использованы в дальнейшем при изучении вариации, дифференциации и структуры национального богатства России.

Ключевые слова: экономика, развитие, основные фонды, национальное богатство, динамика, структура.

\section{Введение}

Российская Федерация является одной из богатейших стран мира в области национального богатства, но его элементы распределены по территории неравномерно, что негативным образом влияет на поступательное развитие экономики и общества. При этом учет таких элементов как природный и человеческий капитал находится на стадии становления, лишь в отношении воспроизводимого капитала дела обстоят лучше. Так в России налажен учет основных фондов и нематериальных активов. В рамках проводимого исследования остановимся на самом значимом для экономике активе, а именно основных фондах и проведем изучение количественных изменений происходящих в их структуре на протяжении 1990-2018 гг.

Обращаясь к научным публикациям, мы находим большое количество материала относительно национального богатства России и основных фондов как самого большого элемента, в качестве авторов занимавшихся этой проблемой можно назвать Латушко Н.А. [4], Никоненко В.А. [5], Фальцман В.К. [8], Хамраев Ф.Б. [9],
Шутько Ю.А. [11]. Непосредственно изучением структуры, динамики и зависимостей основных фондов занимались такие авторы как: Березинская О. [1], Карпушин Е.С. [2], Колесник А.Н. [3], Погосов И.А. [6], Флегонтов В.И. [8], Цыпин А.П. [10]. Опираясь на работы приведенных ученых, проанализируем как изменилась структура основных фондов в России на длительном промежутке времени.

Для получения доказательных выводов и обнаружения сложившихся закономерностей были использованы данные Федеральной службы государственной статистики, в частности сведения из Российского статистического ежегодника. Собранный массив информации обрабатывался с помощью экономико-статистических методов, таких как анализ, сравнения, коэффициентный.

\section{Результаты исследования}

На первом этапе исследования обратимся к сведениям Росстата и проанализируем изменение структуры национального богатства России (рисунок 1).

Официальная статистика выделяет всего три элемента национального богатства и самым 


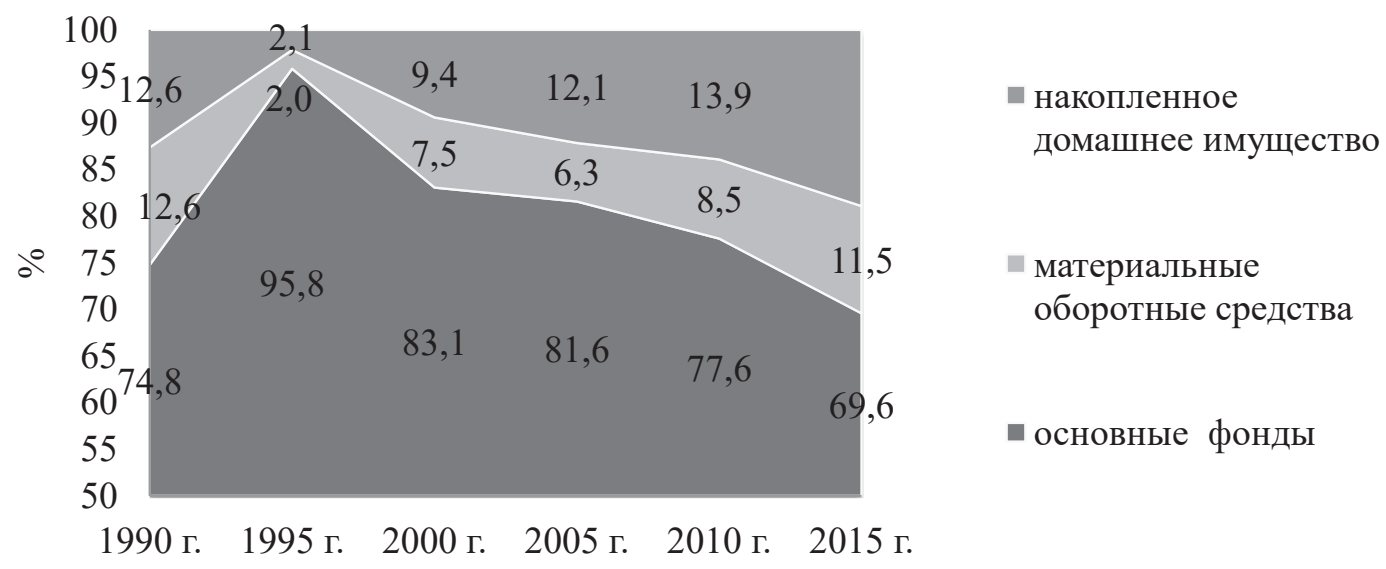

Puc. 1. Структура национального богатства России, \% (Примечание: данные за период 2016-2018 гг. не публикуются Росстатом)

большим из них является основные фонды, согласно представленной информации на их долю приходится около 70\%. Стоит отметить, что удельный вес данной категории постоянно изменяется и, начиная с 2000-х годов имеет тенденцию к снижению. По-видимому, это связано с переходом к так называемой цифровой экономике, в которой все больше место отводится нематериальным объектам - программному обеспечению, искусственному интеллекту и т.д.

Если рассматривать изменение среднегодовой стоимости основных фондов то в абсолютном выражении имеем рост, так в отечном периоде по сравнению с 2017 годом увеличение составило 16,3 трлн. рублей, но если обратится к темпу роста, приведенному на рисунке 2 , то наблюдается траектория к снижению показателя, таким образом, имеем замедление роста основных фондов.

Аналитики связывают замедление темпа роста с кризисами 2008 г. и 2014 г., которые негативно повлияли на экономику страны и как следствие мы наблюдаем более умеренное наращивание рассматриваемого элемента национального богатства.

Далее приступим к рассмотрению структурных изменений основных фондов. Росстат предлагает статистику в следующих разрезах, это деление на государственные и негосударственные. Если в 1990 году соотношение между этими категориями составляло $91 \%$ против 9\%, то в результате приватизации уже в 1992 году в России наблюдалось соотношение $26 \%$ против $74 \%$, а в отчетном периоде $23 \%$ и $77 \%$. По видимому придел, достигнут, и государство больше не намерено передавать активы в частные руки.

В видовой структуре основных фондов коммерческих организаций в 2018 году доминирует категория «сооружения», на их долю приходится $49 \%$, тогда как в некоммерческом секторе наи-

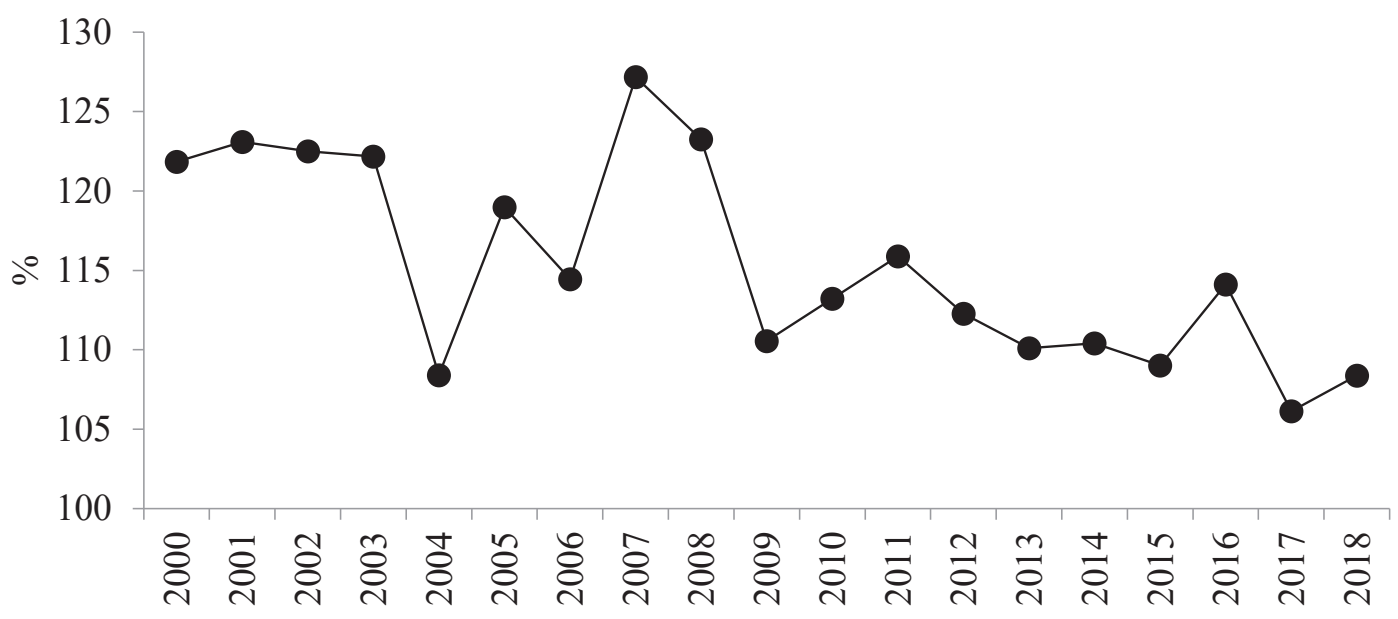

Puc. 2. Темп роста стоимости основных фондов, в \% к предыдущему году 
больший удельный вес имеет категория «здания». Сложившаяся структура объясняется направлением деятельности, а именно производство в первом случае и оказание услуг (образование, здравоохранение и т.д.) во втором.

Самая значимая структура основных фондов, это деление их по видам экономической деятельности в соответствии с ОКВЭД, проведем анализ этой структуры, обратившись к данным таблицы 1.

Как и следовало ожидать, наибольшей долей в общем объеме основных фондов обладает промышленность, значение в 2018 году равно 31\%, далее идет транспорт и связь с $25 \%$, остальные виды экономической деятельности не обла- дают внушительными удельными весами. Для оценки существенности изменения структуры во времени был рассчитан коэффициент структурных сдвигов и различий Рябцева, который равен 0,171 , что классифицируется как умеренное изменение, таким образом, делаем вывод о стабильности структуры во времени.

Как было сказано выше, Россия обладает обширными территориями на которых национальное богатство распределено неравномерно, по этой причине обратимся к рисунку 3 и рассмотрим вариацию удельных весов основных фондов в разрезе федеральных округов.

Приведенные на рисунке 3 сведения наглядно доказывают наличие неравномерности в рас-

Таблица 1. Структура основных фондов России в разрезе видов экономической деятельности,\%

\begin{tabular}{|l|c|c|c|c|c|}
\hline \multicolumn{1}{|c|}{ Отрасли } & 1990 г. & 2000 г. & 2010 г. & 2018 г. & $\begin{array}{c}\text { Отклонения } \\
\text { в } 2018 \text { г. к } \\
1990 \text { г. }\end{array}$ \\
\hline сельское хозяйство & 11,5 & 7,5 & 3,2 & 3,1 & $-8,4$ \\
\hline промышленность & 33,6 & 24,7 & 25,6 & 31,4 & $-2,2$ \\
\hline строительство & 3,7 & 1,8 & 1,6 & 1,3 & $-2,4$ \\
\hline торговля & 2,9 & 1,6 & 3,3 & 2,5 & $-0,4$ \\
\hline транспорт и связь & 14,3 & 20,6 & 27,8 & 25,2 & 10,9 \\
\hline финансовая деятельность & 1,7 & 0,5 & 2,3 & 2,2 & 0,5 \\
\hline $\begin{array}{l}\text { государственное управление и } \\
\text { обеспечение военной безопасности; }\end{array}$ & нос. & 2 & 4,6 & 5,7 & - \\
\hline образование & & & & 2,5 & $-3,7$ \\
\hline здравоохранение & 6,2 & 4,8 & 2,9 & 2,1 & $-0,1$ \\
\hline прочие виды деятельности & 2,2 & 2,1 & 2,3 & 2,1 & 0,2 \\
\hline
\end{tabular}

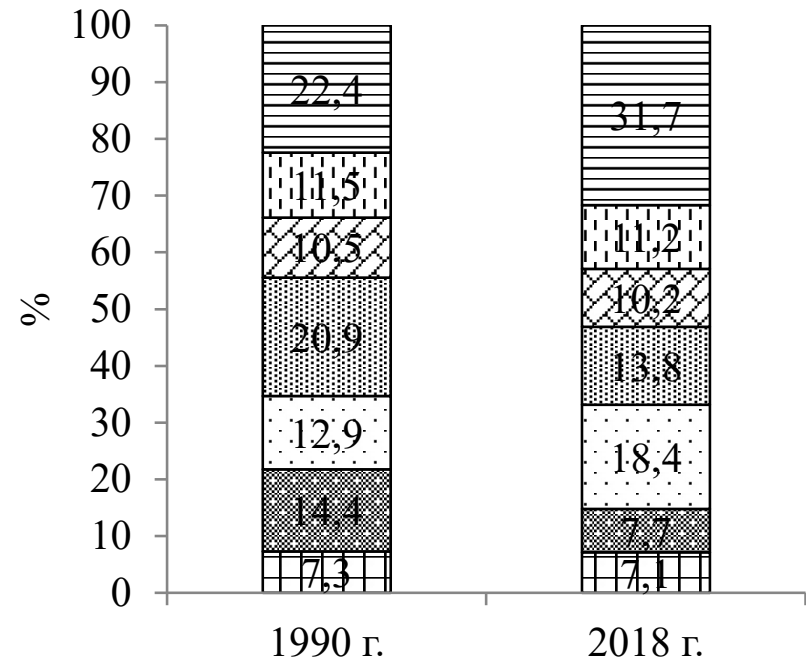

घЦентральный

$\square$ Северо-Западный

■ Южный и Северо-Кавказский

囯 Приволжский

$\square$ Уральский

圆 Сибирский

ஐ Дальневосточный

Puc. 3. Удельные веса основных фонов в разрезе федеральных округов, \% 
пределении основных фондов по территории страны, так наибольший удельный вес наблюдается в Центральном ФО, при этом доля региона увеличилась за рассматриваемый период на 9,3 процентных пункта. Также выросла доля Уральского ФО на 5,5 п.п., тогда как по ПФО имеем снижение на 7,1 п.п. Из сложившейся закономерности можно сделать вывод о концентрации активов в европейской части России и перелив капитала из ПФО и СФО.

При изучении закономерностей развития основных фондов немаловажным является рассмотрение относительных показателей характеризующих их движение, по этой причине обратимся к рисунку 4 и проанализируем динамику коэффициента поступление и выбытия.

Превышение коэффициента выбытия над коэффициентом обновления наблюдалось однажды в 1997 году, далее траектории движения показателей не пересекаются и находятся в противофазе друг к другу.

Коэффициент выбытия на рассматриваемом отрезке времени планомерно снижается, оценка модели приводит нам к уравнению $\mathrm{y}^{\prime}=2,03-0,05 \mathrm{t}$, таким образом можно сделать вывод, что ежегодно показатель снижается на 0,05 п.п.

Движение коэффициента обновления проявляет нелинейную траекторию, но для упрощения моделирования используем только времен- ной отрезок с 1997 года по 2018 год, в результате получаем следующую модель у' $=1,36+0,17 \mathrm{t}$, таким образом, в среднем в год показатель увеличивается на 0,17 п.п. Т.е. для достижения уровня 1990 года в 6,3\% понадобится порядка 7 лет.

\section{Выводы}

Подводя итоги проведенного анализа изменения структуры основных фондов на протяжении 1990-2018 гг. можно сделать ряд выводов и заключений: во-первых, удельный вес основных фондов в структуре национального богатства (а точнее воспроизводимой части национального богатства) снижается, что связано с развитием цифровых технологий; во-вторых, на протяжении рассматриваемого периода наблюдается замедление темпа роста основных фондов, это объясняется чередой внутренних и внешних потрясений, негативно влияющих на народное хозяйство России; в-третьих, до 77\% основных фондов сосредоточены в частных руках, основной вид экономической деятельности, сосредоточивший 31\% всех основных фондов является промышленность, при этом до 32\% всех основных фондов сконцентрированы в Центральном федеральном округе. Полученные вводы указывают, что под влиянием политикоэкономических процессов меняется экономика России, и структура основных фондов как неотъемлемая ее часть.

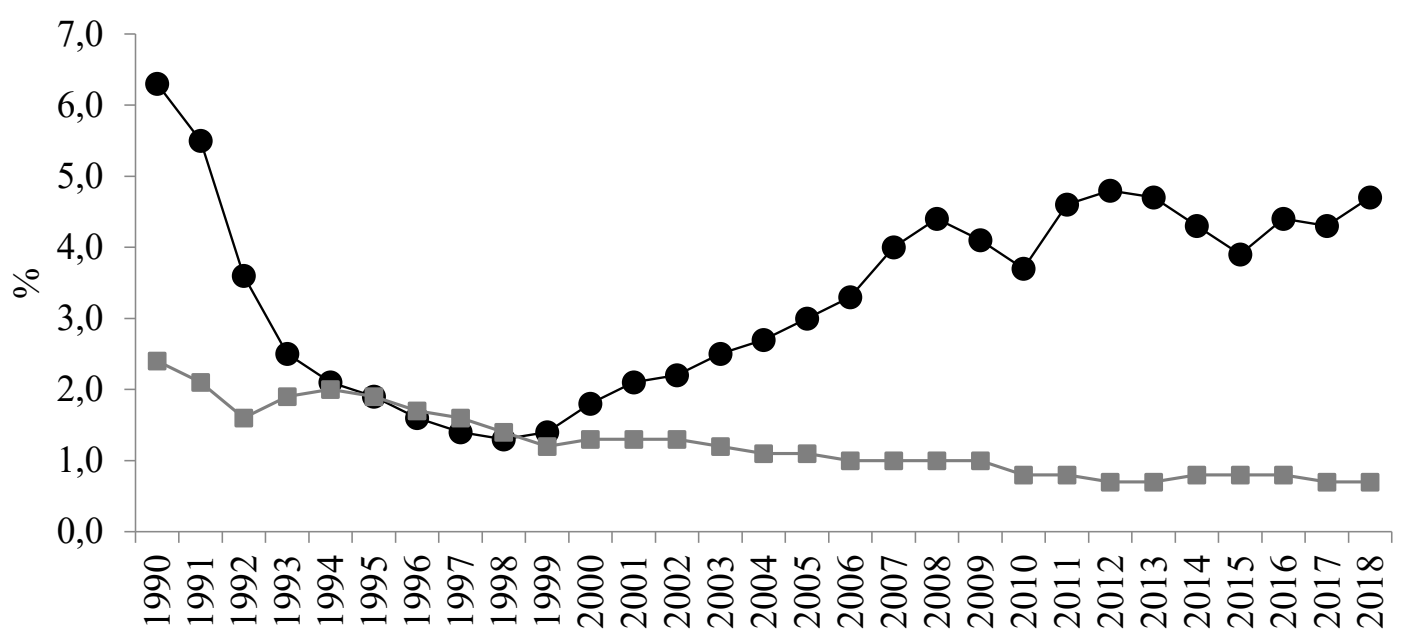

-Коэффициент обновления, \% $\rightarrow$-Коэффициент выбытия, \%

Puc. 4. Динамика коэффициента выбытия и обновления основных фондов в России, \% 


\section{Библиографический список}

1. Березинская О., Щёлокова Д. Перспективы преодоления инвестиционной паузы в экономике России: динамика видов основных фондов // Экономическое развитие России. 2018. Т. 25. № 6. С. 10-14.

2. Карпушин Е.С. Необходимость обновления основных фондов в России как условие инновационного развития // Экономика. Бизнес. Право. 2018. № 10-12 (28). С. 29-34.

3. Колесник А. Н. Анализ изменения наличия основных фондов как показателя экономического роста в России // Наука, техника и образование. 2018. № 5 (46). С. 92-95.

4. Латушко Н.А. Оценка и измерение структуры национального богатства региона: методические подходы // Российский экономический интернет-журнал. 2018. № 4. С. 67.

5. Никоненко В.А. Оценка динамики и эффективности использования национального богатства Российской Федерации // Международный журнал гуманитарных и естественных наук. 2019. № 12-3 (39). С. $106-109$.

6. Погосов И.А. Основной капитал России // Проблемы прогнозирования. 2018. № 4 (169). С. 17-26.

7. Фальцман В.К. О структуре, динамике и использовании активной части национального богатства // Проблемы прогнозирования. 2018. № 5 (170). С. 13-23.

8. Флегонтов В.И. Совершенствование основных фондов РФ как фактор инновационного развития // Актуальные проблемы социально-экономического развития России. 2017. № 4. С. 42-48.

9. Хамраев Ф.Б. Национальное богатство: его структура и эффективность использования Россия и страны мира // Форум молодых ученых. 2018. № 3 (19). С. 692-712.

10. Цыпин А.П., Попов В.В. Статистический анализ основных фондов России: наличие, состояние, эффективность использования // Азимут научных исследований: экономика и управление. 2017. Т. 6. № 3 (20). С. $355-$ 358.

11. Шутько Ю.А. Состав, структура и динамика национального богатства России // НаукаПарк. 2017. № 7 (58). C. 108-110. 